\title{
INVESTIGATION OF FLEXURAL PERFORMANCE OF CONCRETE BEAMS REINFORCED WITH GLASS FIBER REINFORCED POLYMER REBARS
}

\author{
Muhammad A. Muhammad ${ }^{1,{ }^{*}, \text { FARIS R. AHMED }}{ }^{* *}$ and SerWan KH. RAFiQ ${ }^{*}$ \\ *Dept. of Civil Engineering, College of Engineering, University of Sulaimani, \\ Kurdistan Region-Iraq \\ ** Dept. of Civil Engineering, Faculty of Engineering, University OF Koya, Kurdistan Region-Iraq
}

(Accepted for Publication: December 8, 2020)

\begin{abstract}
As a solution of steel corrosion, glass fiber reinforced polymer (GFRP) rebars have been recommended to be used as internal reinforcement instead of steel reinforcement during last two decades. Lightweight, no-corrosion, thermal conductivity, electrically and magnetically resistance, and higher tensile strength are main advantageous properties of GFRP rebars over steel reinforcement. However, it has been noted that the recommended design codes in this field still require modifications. Some studies were conducted on concrete structures reinforced with this new reinforcing material worldwide. In this paper, test data of fifty-three concrete beams reinforced with GFRP rebars were collected from eight different works to investigate cracking moment, nominal moment, deflection and neutral axis depth. The selected beams were reinforced with steel stirrups and GFRP rebars in traverse and longitudinal directions, respectively. The beams were tested under four-points loading test to fail in flexure. A comprehensive approach to calculate both experimental and predicted results is given in terms of deflection and flexural capacity. The experimental results are compared with calculated design results according to ACI 440.1R-15. Statistical data analysis is performed for both theoretical and experimental results. In conclusion, the multiplier factors for theoretical cracking moment, nominal moment, ultimate deflection and neutral axis depth have been proposed to be $0.94,1.25,1.4$ and 0.806 , respectively.
\end{abstract}

KEYWORDS: Concrete Beam; Glass Fiber Reinforced Polymer Rebar; Deflection; Moment Capacity; Four Point Loading Test; ACI 440.1R-15

\section{Notation}

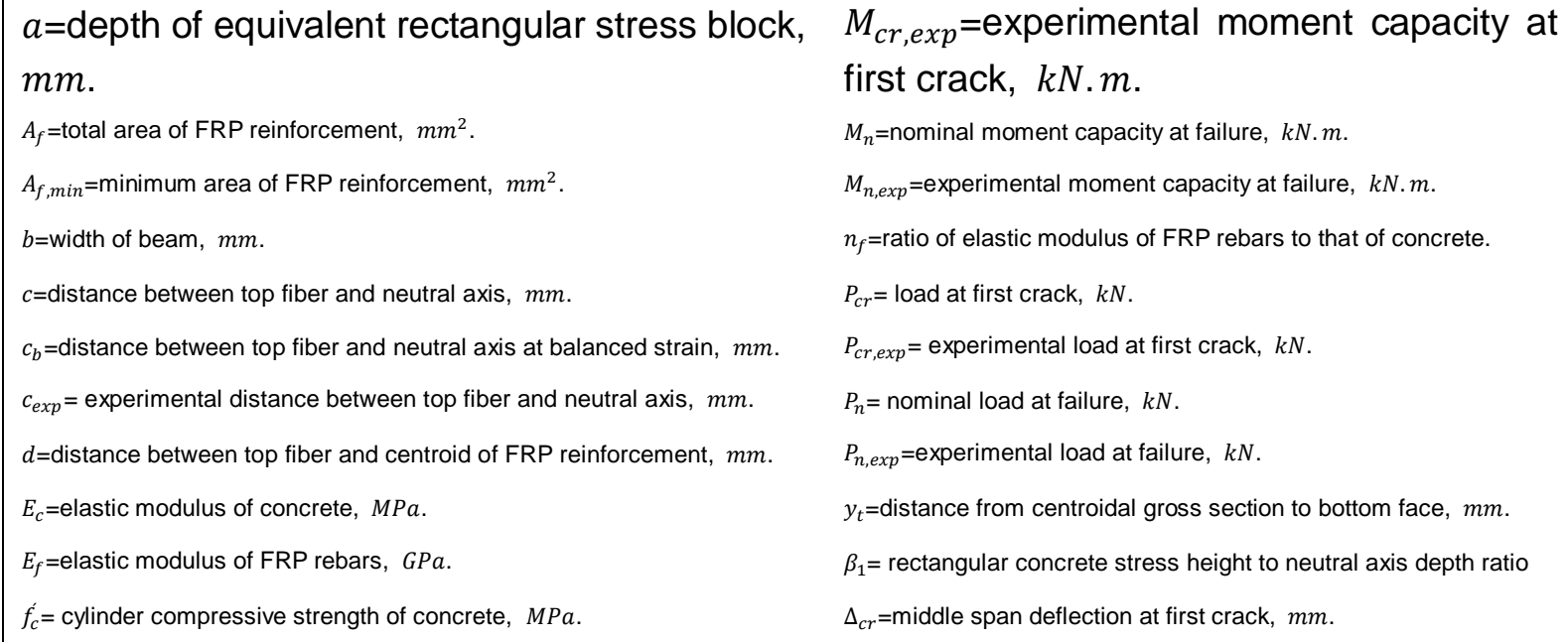

muhammad.rashid@univsul.edu.iq; faris.rashied@koyauniversity.org; serwan.rafiq@univsul.edu.iq 


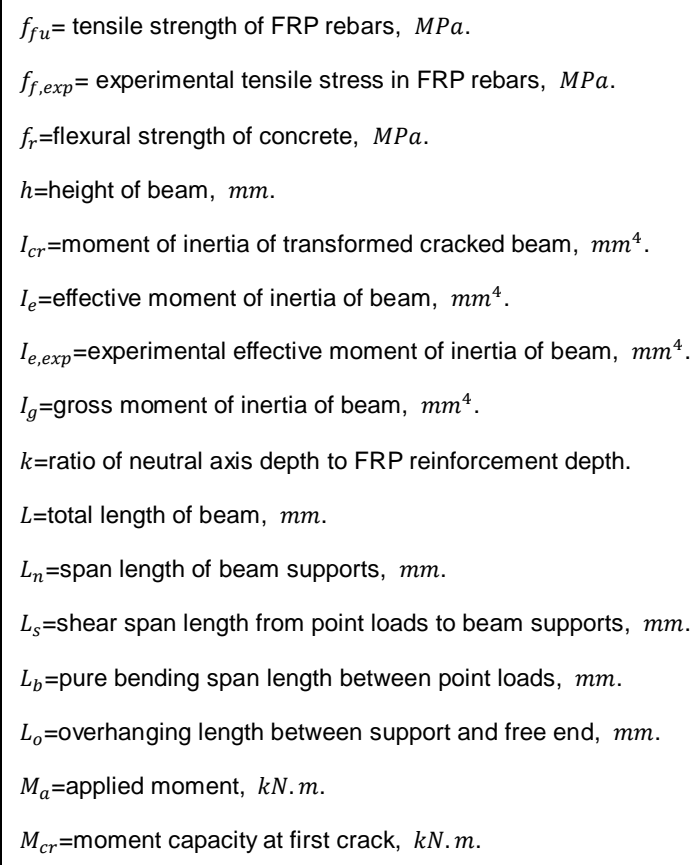

\section{INTRODUCTION}

O ver the world numerous steel reinforced concrete structures have been exposed to steel corrosion in serious environments and structural deterioration resulting in expensive rehabilitation and lockdown of facilities. To solve corrosion issue, the use of glass fiber reinforced polymer (GFRP) bars as internal reinforcement has developed as a promising alternative of traditional steel reinforcement. Besides noncorrosive nature of GFRP rebars, they also have high tensile strength, lightweight, lower thermal conductivity, electromagnetic neutrality, and these advantages over steel make GFRP attractive as internal reinforcement to be applied in concrete structures.

Reinforced concrete members with GFRP perform differently from those reinforced with steel. GFRP rebars have linear stress strain relationship up to GFRP rupture, and resulting in sudden structural failure without warning. In addition, modulus of elasticity of the GFRP bars is lower than that of steel (Bank 2006). Therefore, for the same reinforcement ratio, reinforced concrete members with GFRP :muhammad.rashid@univsul.edu.iq; serwan.rafiq@univsul.edu.iq ${ }^{1}$ Corresponding author: College of Engineering, University of Sulaimani, Kurdistan Region, Iraq.

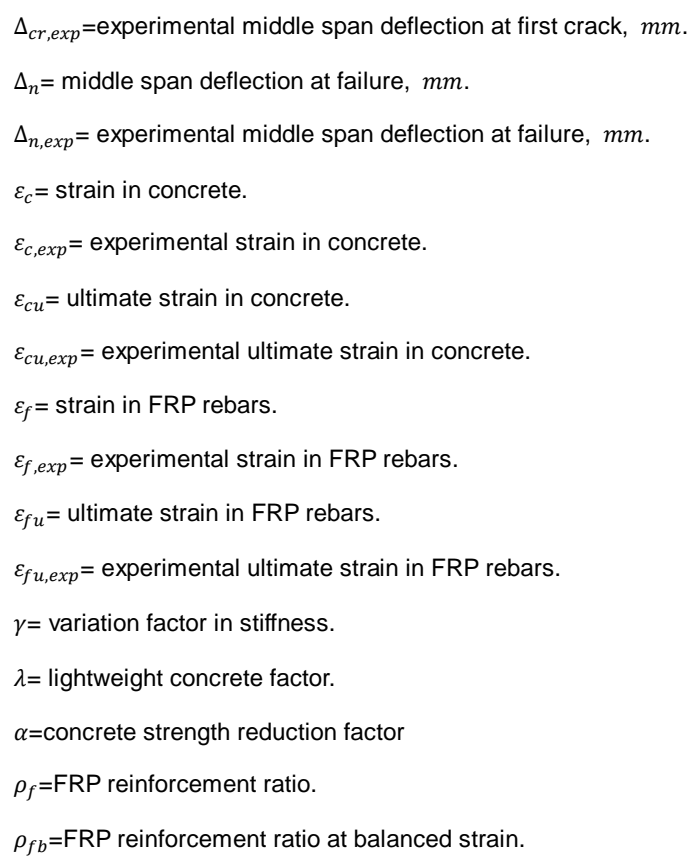

comparing to steel have greater deflection and crack widths (Tighiouart et al 1998). Hence, the design of GFRP reinforced concrete members is typically governed by serviceability requirements more than strength requirements. Owing to the brittle behavior of GFRP rebar and concrete, it is recommended to predict moment capacity with concrete mode of failure than GFRP rupture to avoid sudden collapse because concrete crushing is more progressive and resulting in less catastrophic failure (ACI Committee 440 2015).

GFRP rebars has been commonly manufactured for concrete reinforcement over the last two decades. Annual estimated amount of FRP used in construction is over 10 million meters (Burgoyne et al 2007). Many GFRP plants are a commercially available to produce GFRP rebar, which are mostly on request demand. Due to the dispersion of FRP market and lack of well-founded international standards, a wide range of GFRP products are existing on the market (Emparanza et al 2018). The GFRP products have a wide range of surface texture, such as smooth, helically deformed, warped, ribbed, sand coated, which affects the bonding faris.rashied@koyauniversity.org; 
behaviors. In addition, GFRP rebars have also different mechanical properties are such as tensile strength and modulus of elasticity. On the other hand, Most of GFRP design codes and guides use those equations applied for steel reinforced concrete members with some amendments to comprise the alterations in the mechanical properties between GFRP and steel rebars. Therefore, establishing equations to find the GFRP performance may produce reasonable estimates with one type of FRP bars but disagreements with another type.

Over the last decades, a number of research studies were carried out to the flexural performance of GFRP reinforced concrete beams (Benmokrane et al 1995; Alsayed et al 2000; Toutanji \& Saafi, 2000; Ashour 2006; Kalpana \& Subramanian 2011; Goldston et al 2016; El-Nemr et al 2018). In these studies, the effects of normal and high strength concrete on the flexural behavior of GFRP reinforced beams were investigated. In addition, GFRP configuration, reinforcement ratio, different GFRP rebar with different mechanical properties have been considered as experimental parameters. In the study case of deflections, some coefficients were proposed to predict the effective moment of inertia concrete beams reinforced with GFRP rebar (Bischoff 2005). It was reported that ACI 440 calculations predicted conservative ultimate moment and underestimated failure deflections as well. however, these predictions vary among research studies. This paper covers the deflection and flexural moment capacity of concrete beams reinforced with GFRP rebar as longitudinal flexural reinforcement and steel stirrups. The database was made to collect the pure bending test data of 53 GFRP reinforced beams from 8 different experimental studies. The beams were theoretically designed according to the design recommendations in ACI 440.1R-15. Experimental test results were also compared

muhammad.rashid@univsul.edu.iq; faris.rashied@koyauniversity.org; serwan.rafiq@univsul.edu.iq with those of the theoretical design to investigate the applicability of the code.

\section{Experimental Database}

The results of 53 concrete beam reinforced with GFRP rebars were collected from eight different research studies from the literature (Toutanji and Deng 2003; Barris et al 2009; Wang and Belarbi 2011; Kassem et al 2011; Adam et al 2015; Goldston et al 2016; El-Nemr et al 2018; El Refai et al 2015). The beams were tested under four points flexural test at the age of 28 days. The beams cover a variety of dimensions whereas the instrumental schematic side view of tested beams was similar as shown in Figure 1. All beams were designed with adequate shear resistance using steel stirrups and expected to fail in flexure. Table 1 presents the GFRP rebars and concrete properties used in the beams design. GFRP rebars had different diameters ranged between (6.35-25) $\mathrm{mm}$. The reinforcement area was computed according to the actual bar diameter instead of using nominal area. GFRP modulus of elasticity and tensile strength also vary between (30-69) GPa, (551-1764) MPa, respectively. Furthermore, the compressive strengths of concrete included in the database differs from $20 \mathrm{MPa}$ to $80 \mathrm{MPa}$. Table 2 gives the GFRP flexural reinforcement detail and dimensional properties for each beam. The beams had various total length and clear span ranges between (2032-4250) $\mathrm{mm}$ and (1800-3750) mm, respectively. The beams have two kind of reinforcement arrangements in one or two layers, and their effective depth calculated from extreme compression fiber to the centroid of GFRP rebar according to moment of areas of bars. The rate of loading had been strain controlled (deflection rate per time) or load controlled (load increments). Rates of loading for strain controlled differed from 0.6 to 1.2 $\mathrm{mm} / \mathrm{min}$ while for load controlled ranged

between 13 to 70 increments.

ty of Sulaimani, Kurdistan Region, Iraq. 


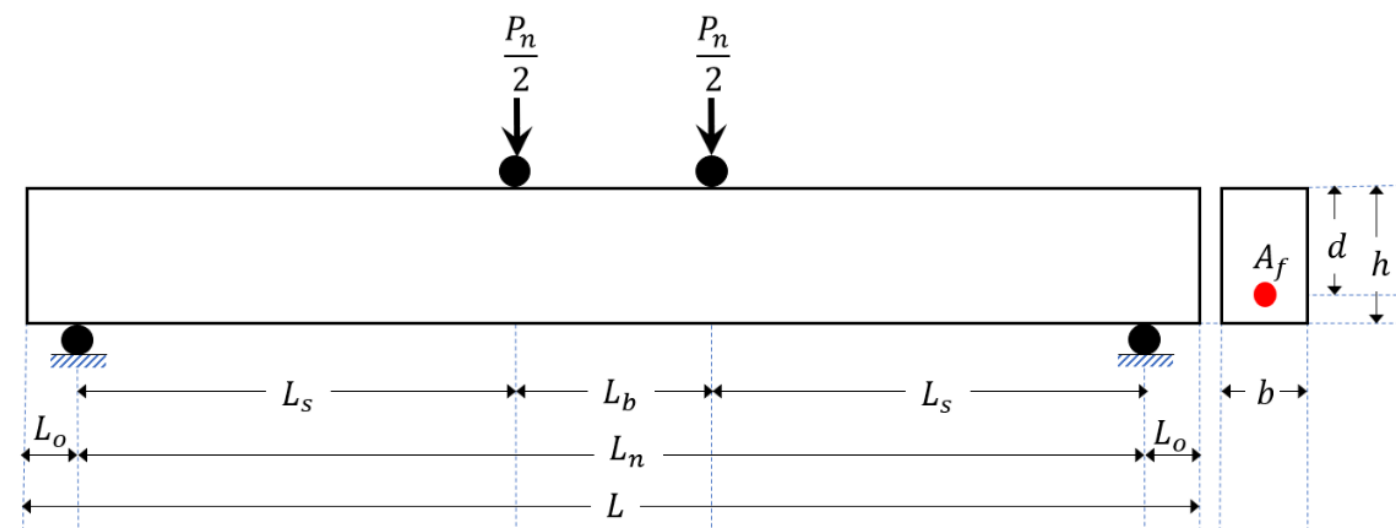

Fig. (1): Beam instrumental setup for four points loading test

Table (1): GFRP rebar and concrete mechanical properties used in test beams

\begin{tabular}{|c|c|c|c|c|c|c|c|c|c|}
\hline \multirow[t]{2}{*}{ Reference } & \multirow[t]{2}{*}{ Beam ID } & \multicolumn{6}{|c|}{ GFRP rebar properties } & \multicolumn{2}{|c|}{$\begin{array}{l}\text { Concrete } \\
\text { properties }\end{array}$} \\
\hline & & $\begin{array}{l}\text { Dia. } \\
m m\end{array}$ & $\begin{array}{c}A_{f} \\
m m^{2}\end{array}$ & $\begin{array}{l}E_{f}, \\
G P a\end{array}$ & $\begin{array}{l}f_{f u}, \\
M P a\end{array}$ & $\begin{array}{c}\varepsilon_{f u}, \\
\mathrm{~mm} / \mathrm{mm}\end{array}$ & Surface texture & $\begin{array}{c}f_{c}, \\
M P a\end{array}$ & $E_{c}, M P a$ \\
\hline \multirow{4}{*}{$\begin{array}{l}\text { Kassem et al } \\
\text { (2011) }\end{array}$} & G1-6 & 12.7 & 760 & 40.0 & 617 & 0.0150 & sand coat & 39.05 & 29300 \\
\hline & G1-8 & 12.7 & 1013 & 40.0 & 617 & 0.0150 & sand coat & 39.05 & 29300 \\
\hline & G2-6 & 12 & 679 & 36.0 & 747 & 0.0180 & Ribbed deformed & 39.05 & 29300 \\
\hline & G2-8 & 12 & 905 & 36.0 & 747 & 0.0180 & Ribbed deformed & 39.05 & 29300 \\
\hline \multirow{17}{*}{$\begin{array}{l}\text { El-Nemr et al } \\
(2018)\end{array}$} & 3\#13G1 & 13 & 398 & 48.7 & 817 & 0.0170 & sand coated & 33.5 & 27203 \\
\hline & $5 \# 13 G 1$ & 13 & 664 & 48.7 & 817 & 0.0170 & sand coated & 38.95 & 29333 \\
\hline & $2 \# 13 G 2$ & 13 & 265 & 67.0 & 1639 & 0.0250 & sand coated & 33.5 & 27203 \\
\hline & $3 \# 15 G 1$ & 15.9 & 596 & 48.1 & 751 & 0.0160 & sand coated & 38.95 & 29333 \\
\hline & 4\#15G1 & 15.9 & 794 & 48.1 & 751 & 0.0160 & sand coated & 38.95 & 29333 \\
\hline & $2 \# 15 G 2$ & 15.9 & 397 & 69.3 & 1362 & 0.0200 & sand coated & 29 & 25310 \\
\hline & 2\#15G3 & 15.9 & 397 & 59.5 & 1245 & 0.0210 & helically grooved & 33.83 & 27337 \\
\hline & $6 \# 15 \mathrm{G} 1$ & 15.9 & 1191 & 48.1 & 751 & 0.0160 & sand coated & 33.5 & 27203 \\
\hline & $5 \# 15 G 2$ & 15.9 & 993 & 69.3 & 1362 & 0.0200 & sand coated & 29 & 25310 \\
\hline & $5 \# 15 G 3$ & 15.9 & 993 & 59.5 & 1245 & 0.0210 & helically grooved & 33.8 & 27325 \\
\hline & 2\#20G1 & 20 & 628 & 47.6 & 728 & 0.0150 & sand coated & 38.95 & 29333 \\
\hline & 3\#20G1 & 20 & 942 & 47.6 & 728 & 0.0150 & sand coated & 42.1 & 30496 \\
\hline & 2\#22G1 & 22 & 760 & 46.4 & 693 & 0.0150 & sand coated & 38.95 & 29333 \\
\hline & 3\#20G2 & 20 & 942 & 52.5 & 1082 & 0.0210 & sand coated & 48.13 & 32607 \\
\hline & 2\#25G1 & 25 & 982 & 53.2 & 666 & 0.0130 & sand coated & 48.13 & 32607 \\
\hline & $2 \# 25 \mathrm{G} 2$ & 25 & 982 & 66.3 & 1132 & 0.0170 & sand coated & 48.13 & 32607 \\
\hline & 2\#25G3 & 25 & 982 & 60.3 & 906 & 0.0150 & helically grooved & 33.8 & 27325 \\
\hline Wang & P4G-1 & 13 & 664 & 41.0 & 690 & 0.0168 & sand coated & 48 & 32563 \\
\hline Belarbi (2011) & P8G-1 & 25 & 982 & 41.0 & 551 & 0.0134 & sand coated & 48 & 32563 \\
\hline Toutanji & GB1-1 & 12.7 & 253 & 40.0 & 695 & 0.0174 & $N G$ & 35 & 35000 \\
\hline
\end{tabular}

:muhammad.rashid@univsul.edu.iq; faris.rashied@koyauniversity.org; serwan.rafiq@univsul.edu.iq

${ }^{1}$ Corresponding author: College of Engineering, University of Sulaimani, Kurdistan Region, Iraq. 
Journal of University of Duhok, Vol.23, No.2 (Pure and Eng. Sciences), Pp 630-647, 2020 (Special Issue)

$3^{\text {rd }}$ international conference on recent innovations in engineering (ICRIE) Duhok, September 9-10-2020

\begin{tabular}{|c|c|c|c|c|c|c|c|c|c|}
\hline \multirow[t]{5}{*}{ Deng (2003) } & GB1-2 & 12.7 & 253 & 40.0 & 695 & 0.0174 & $N G$ & 35 & 35000 \\
\hline & GB2-1 & 12.7 & 380 & 40.0 & 695 & 0.0174 & $N G$ & 35 & 35000 \\
\hline & GB2-2 & 12.7 & 380 & 40.0 & 695 & 0.0174 & $N G$ & 35 & 35000 \\
\hline & GB3-1 & 12.7 & 507 & 40.0 & 695 & 0.0174 & $N G$ & 35 & 35000 \\
\hline & GB3-2 & 12.7 & 507 & 40.0 & 695 & 0.0174 & $N G$ & 35 & 35000 \\
\hline \multirow{3}{*}{$\begin{array}{l}\text { El Refai et al } \\
(2015)\end{array}$} & $2 \mathrm{G} 12$ & 12 & 226 & 50.0 & 1000 & 0.0200 & $N G$ & 40 & 29725 \\
\hline & $3 G 12$ & 12 & 339 & 50.0 & 1000 & 0.0200 & $N G$ & 40 & 29725 \\
\hline & $3 \mathrm{G} 16$ & 16 & 603 & 50.0 & 1000 & 0.0200 & $N G$ & 40 & 29725 \\
\hline \multirow{6}{*}{$\begin{array}{l}\text { Barris et al } \\
(2009)\end{array}$} & C-212-D1 & 12 & 226 & 63.3 & 1353 & 0.0210 & spirally ribbed & 59.8 & 26939 \\
\hline & C-216-D1 & 16 & 402 & 64.2 & 995 & 0.0160 & spirally ribbed & 56.3 & 26524 \\
\hline & C-316-D1 & 16 & 603 & 64.2 & 995 & 0.0160 & spirally ribbed & 55.3 & 24926 \\
\hline & C-212-D2 & 12 & 226 & 63.3 & 1353 & 0.0210 & spirally ribbed & 39.6 & 23163 \\
\hline & C-216-D2 & 16 & 402 & 64.2 & 995 & 0.0160 & spirally ribbed & 61.7 & 27318 \\
\hline & C-316-D2 & 16 & 603 & 64.2 & 995 & 0.0160 & spirally ribbed & 60.1 & 26910 \\
\hline \multirow{6}{*}{$\begin{array}{l}\text { Goldston et al } \\
(2016)\end{array}$} & $40-\# 2-0.5-S$ & 6.35 & 63 & 37.5 & 732 & 0.0196 & $N G$ & 40 & 29725 \\
\hline & 40-\#3-1.0-S & 9.53 & 143 & 55.6 & 1764 & 0.0318 & $N G$ & 40 & 29725 \\
\hline & 40-\#4-2.0-S & 12.7 & 253 & 48.6 & 1605 & 0.0330 & $N G$ & 40 & 29725 \\
\hline & $80-\# 2-0.5-S$ & 6.35 & 63 & 37.5 & 732 & 0.0196 & $N G$ & 80 & 42038 \\
\hline & 80-\#3-1.0-S & 9.53 & 143 & 55.6 & 1764 & 0.0318 & $N G$ & 80 & 42038 \\
\hline & $80-\# 4-2.0-S$ & 12.7 & 253 & 48.6 & 1605 & 0.0330 & $N G$ & 80 & 42038 \\
\hline \multirow{9}{*}{$\begin{array}{l}\text { Adam et al } \\
(2015)\end{array}$} & A25-1 & 8 & 101 & 30.0 & 640 & 0.0200 & Ribbed deformed & 19.6 & 20808 \\
\hline & A25-2 & 8,12 & 163 & 30.0 & 640 & 0.0200 & Ribbed deformed & 19.6 & 20808 \\
\hline & A25-3 & 8,12 & 277 & 30.0 & 640 & 0.0200 & Ribbed deformed & 19.6 & 20808 \\
\hline & A45-1 & 8,12 & 163 & 30.0 & 640 & 0.0200 & Ribbed deformed & 38.4 & 29125 \\
\hline & A45-2 & 8,12 & 277 & 30.0 & 640 & 0.0200 & Ribbed deformed & 38.4 & 29125 \\
\hline & A45-3 & 12 & 452 & 30.0 & 640 & 0.0200 & Ribbed deformed & 38.4 & 29125 \\
\hline & A70-1 & 8,12 & 277 & 30.0 & 640 & 0.0200 & Ribbed deformed & 59.52 & 36260 \\
\hline & A70-2 & 12 & 452 & 30.0 & 640 & 0.0200 & Ribbed deformed & 59.52 & 36260 \\
\hline & A70-3 & 12 & 679 & 30.0 & 640 & 0.0200 & Ribbed deformed & 59.52 & 36260 \\
\hline
\end{tabular}

Table (2):GFRP rebar configuration, GFRP reinforcement ratios and test beam dimensions

\begin{tabular}{|c|c|c|c|c|c|c|c|c|c|c|}
\hline Reference & Beam ID & GFRP rebar Configuration & $\begin{array}{c}L, \\
m m\end{array}$ & $\begin{array}{c}b, \\
m m\end{array}$ & $\begin{array}{c}h, \\
m m\end{array}$ & $\begin{array}{c}L_{n} \\
m m\end{array}$ & $\begin{array}{c}L_{s}, \\
m m\end{array}$ & $\begin{array}{c}d, \\
m m\end{array}$ & $\begin{array}{c}\rho_{f}, \\
\%\end{array}$ & $\begin{array}{c}\rho_{f b} \\
\%\end{array}$ \\
\hline \multirow{4}{*}{$\begin{array}{l}\text { Kassem et al } \\
\text { (2011) }\end{array}$} & G1-6 & $6 \# 12.7 \mathrm{~mm}-2$ rows & 3300 & 200 & 300 & 2750 & 875 & 232 & 1.64 & 0.68 \\
\hline & G1-8 & $8 \# 12.7 \mathrm{~mm}-2$ rows & 3300 & 200 & 300 & 2750 & 875 & 232 & 2.18 & 0.68 \\
\hline & G2-6 & $6 \# 12 \mathrm{~mm}-2$ rows & 3300 & 200 & 300 & 2750 & 875 & 233 & 1.46 & 0.43 \\
\hline & G2-8 & $8 \# 12 \mathrm{~mm}-2$ rows & 3300 & 200 & 300 & 2750 & 875 & 233 & 1.94 & 0.43 \\
\hline \multirow{3}{*}{$\begin{array}{l}\text { El-Nemr et al } \\
(2018)\end{array}$} & 3\#13G1 & $3 \# 13 \mathrm{~mm}-1$ row & 4250 & 200 & 400 & 3750 & 1375 & 354 & 0.56 & 0.43 \\
\hline & $5 \# 13 G 1$ & $5 \# 13 \mathrm{~mm}-1$ row & 4250 & 200 & 400 & 3750 & 1375 & 344 & 0.97 & 0.47 \\
\hline & 2\#13G2 & $2 \# 13 \mathrm{~mm}-1$ row & 4250 & 200 & 400 & 3750 & 1375 & 344 & 0.39 & 0.15 \\
\hline
\end{tabular}

:muhammad.rashid@univsul.edu.iq; faris.rashied@koyauniversity.org; serwan.rafiq@univsul.edu.iq

$634{ }^{1}$ Corresponding author: College of Engineering, University of Sulaimani, Kurdistan Region, Iraq. 
Journal of University of Duhok, Vol.23, No.2 (Pure and Eng. Sciences), Pp 630-647, 2020 (Special Issue)

$3^{\text {rd }}$ international conference on recent innovations in engineering (ICRIE) Duhok, September 9-10-2020

\begin{tabular}{|c|c|c|c|c|c|c|c|c|c|c|}
\hline & 3\#15G1 & 3\#15.9mm - 1 row & 4250 & 200 & 400 & 3750 & 1375 & 343 & 0.87 & 0.55 \\
\hline & 4\#15G1 & $4 \# 15.9 \mathrm{~mm}-1$ row & 4250 & 200 & 400 & 3750 & 1375 & 343 & 1.16 & 0.55 \\
\hline & $2 \# 15 G 2$ & $2 \# 15.9 \mathrm{~mm}-1$ row & 4250 & 200 & 400 & 3750 & 1375 & 343 & 0.58 & 0.20 \\
\hline & $2 \# 15 G 3$ & 2\#15.9mm - 1 row & 4250 & 200 & 400 & 3750 & 1375 & 343 & 0.58 & 0.23 \\
\hline & $6 \# 15 G 1$ & $6 \# 15.9 \mathrm{~mm}-2$ rows & 4250 & 200 & 400 & 3750 & 1375 & 320 & 1.86 & 0.50 \\
\hline & $5 \# 15 G 2$ & $5 \# 15.9 \mathrm{~mm}-2$ rows & 4250 & 200 & 400 & 3750 & 1375 & 331 & 1.50 & 0.20 \\
\hline & $5 \# 15 G 3$ & $5 \# 15.9 \mathrm{~mm}-2$ rows & 4250 & 200 & 400 & 3750 & 1375 & 331 & 1.50 & 0.23 \\
\hline & 2\#20G1 & $2 \# 20 m m$ - 1 row & 4250 & 200 & 400 & 3750 & 1375 & 340 & 0.92 & 0.58 \\
\hline & 3\#20G1 & $3 \# 20 \mathrm{~mm}$ - 1 row & 4250 & 200 & 400 & 3750 & 1375 & 340 & 1.39 & 0.60 \\
\hline & 2\#22G1 & 2\#22mm - 1 row & 4250 & 200 & 400 & 3750 & 1375 & 339 & 1.12 & 0.62 \\
\hline & 3\#20G2 & $3 \# 20 \mathrm{~mm}$ - 1 row & 4250 & 200 & 400 & 3750 & 1375 & 340 & 1.39 & 0.34 \\
\hline & 2\#25G1 & 2\#25mm-1 row & 4250 & 200 & 400 & 3750 & 1375 & 338 & 1.45 & 0.84 \\
\hline & $2 \# 25 G 2$ & $2 \# 25 \mathrm{~mm}$ - 1 row & 4250 & 200 & 400 & 3750 & 1375 & 338 & 1.45 & 0.38 \\
\hline & $2 \# 25 G 3$ & $2 \# 25 \mathrm{~mm}$ - 1 row & 4250 & 200 & 400 & 3750 & 1375 & 338 & 1.45 & 0.43 \\
\hline Wang and & P4G-1 & $5 \# 13 \mathrm{~mm}-1$ row & 2032 & 178 & 229 & 1828 & 711 & 185 & 2.02 & 0.63 \\
\hline Belarbi (2011) & P8G-1 & 2 \#25mm - 1 row & 2032 & 178 & 229 & 1828 & 711 & 178 & 3.09 & 0.96 \\
\hline Toutanji and & GB1-1 & 2\#12.7mm - 1 row & 3000 & 180 & 300 & 2800 & 1200 & 268 & 0.53 & 0.50 \\
\hline \multirow[t]{5}{*}{ Deng (2003) } & GB1-2 & 2\#12.7mm - 1 row & 3000 & 180 & 300 & 2800 & 1200 & 268 & 0.53 & 0.50 \\
\hline & GB2-1 & 3\#12.7mm - 1 row & 3000 & 180 & 300 & 2800 & 1200 & 268 & 0.79 & 0.50 \\
\hline & GB2-2 & 3\#12.7mm - 1 row & 3000 & 180 & 300 & 2800 & 1200 & 268 & 0.79 & 0.50 \\
\hline & GB3-1 & $4 \# 12.7 \mathrm{~mm}-2$ row & 3000 & 180 & 300 & 2800 & 1200 & 255 & 1.10 & 0.50 \\
\hline & GB3-2 & $4 \# 12.7 \mathrm{~mm}-2$ row & 3000 & 180 & 300 & 2800 & 1200 & 255 & 1.10 & 0.50 \\
\hline \multirow{3}{*}{$\begin{array}{l}\text { El Refai et al } \\
(2015)\end{array}$} & $2 \mathrm{G} 12$ & $2 \# 12 \mathrm{~mm}-1$ row & 4000 & 230 & 300 & 3700 & 1250 & 244 & 0.40 & 0.34 \\
\hline & $3 G 12$ & $3 \# 12 \mathrm{~mm}$ - 1 row & 4000 & 230 & 300 & 3700 & 1250 & 244 & 0.60 & 0.34 \\
\hline & $3 G 16$ & $3 \# 16 \mathrm{~mm}-1$ row & 4000 & 230 & 300 & 3700 & 1250 & 242 & 1.08 & 0.34 \\
\hline \multirow{6}{*}{$\begin{array}{l}\text { Barris et al } \\
(2009)\end{array}$} & C-212-D1 & $2 \# 12 \mathrm{~mm}-1$ row & 2050 & 140 & 190 & 1800 & 600 & 163 & 0.99 & 0.30 \\
\hline & C-216-D1 & $2 \# 16 \mathrm{~mm}-1$ row & 2050 & 140 & 190 & 1800 & 600 & 162 & 1.77 & 0.51 \\
\hline & C-316-D1 & $3 \# 16 \mathrm{~mm}-1$ row & 2050 & 140 & 190 & 1800 & 600 & 162 & 2.66 & 0.50 \\
\hline & C-212-D2 & $2 \# 12 \mathrm{~mm}-1$ row & 2050 & 160 & 190 & 1800 & 600 & 143 & 0.99 & 0.23 \\
\hline & C-216-D2 & $2 \# 16 \mathrm{~mm}-1$ row & 2050 & 160 & 190 & 1800 & 600 & 141 & 1.78 & 0.56 \\
\hline & C-316-D2 & $3 \# 16 \mathrm{~mm}-1$ row & 2050 & 160 & 190 & 1800 & 600 & 141 & 2.67 & 0.54 \\
\hline \multirow{6}{*}{$\begin{array}{l}\text { Goldston et al } \\
(2016)\end{array}$} & 40-\#2-0.5-S & $2 \# 6.35 \mathrm{~mm}-1$ row & 2400 & 100 & 150 & 2000 & 667 & 128 & 0.50 & 0.47 \\
\hline & 40-\#3-1.0-S & 2\#9.53mm - 1 row & 2400 & 100 & 150 & 2000 & 667 & 126 & 1.13 & 0.13 \\
\hline & 40-\#4-2.0-S & 2\#12.7mm - 1 row & 2400 & 100 & 150 & 2000 & 667 & 125 & 2.03 & 0.13 \\
\hline & $80-\# 2-0.5-S$ & 2\#6.35mm - 1 row & 2400 & 100 & 150 & 2000 & 667 & 128 & 0.50 & 0.80 \\
\hline & 80-\#3-1.0-S & 2\#9.53mm - 1 row & 2400 & 100 & 150 & 2000 & 667 & 126 & 1.13 & 0.22 \\
\hline & 80-\#4-2.0-S & 2\#12.7mm - 1 row & 2400 & 100 & 150 & 2000 & 667 & 125 & 2.03 & 0.23 \\
\hline \multirow{3}{*}{$\begin{array}{l}\text { Adam et al } \\
(2015)\end{array}$} & A25-1 & $2 \# 8 m m-1$ row & 2800 & 120 & 300 & 2500 & 1100 & 250 & 0.34 & 0.27 \\
\hline & A25-2 & $1 \# 12 \mathrm{~mm}+1 \# 8 \mathrm{~mm}$ & 2800 & 120 & 300 & 2500 & 1100 & 250 & 0.54 & 0.27 \\
\hline & A25-3 & $2 \# 12 \mathrm{~mm}+1 \# 8 \mathrm{~mm}$ & 2800 & 120 & 300 & 2500 & 1100 & 250 & 0.92 & 0.27 \\
\hline
\end{tabular}

:muhammad.rashid@univsul.edu.iq; faris.rashied@koyauniversity.org; serwan.rafiq@univsul.edu.iq

${ }^{1}$ Corresponding author: College of Engineering, University of Sulaimani, Kurdistan Region, Iraq. 


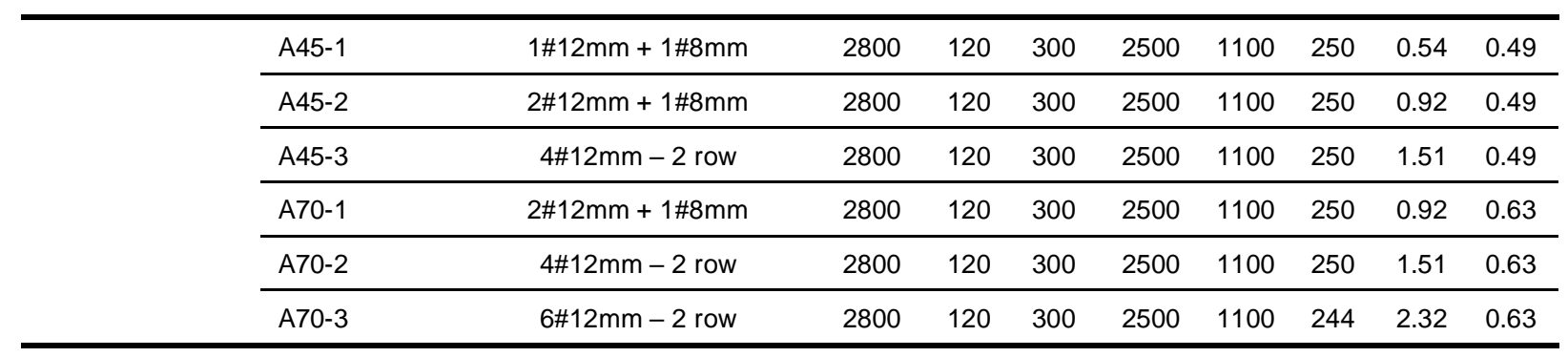

\section{METHODOLOGY}

\subsection{Flexural Moment Capacity}

The theoretical method explained below is based on the recommendations reported by ACI Committee 440 (2015). All 53 beams tested were simply supported and designed to follow one of the three failure modes. Tension control in bottom of the beam where GFRP rebars ruptured during loading or compression control in top of the beam where concrete failure occurs up to reaching ultimate compressive strain. The beam may fail in both tension and compression simultaneously, which is called balanced failure. Classification of failure modes depends on the provided reinforcement ratio $\rho_{f}$ and the balanced reinforcement ratio $\rho_{f b}$ as given in Equation (1) and (2), respectively. When $\rho_{f}<\rho_{f b}$, the beam will fail in tension. When $\rho_{f}>\rho_{f b}$, top fiber of concrete was expected to suffer crushing failure. in case of $\rho_{f}=\rho_{f b}$, the failure mode is expected to be balanced failure. It was reported that failure in GFRP or concrete is catastrophic without warning. According to ACI Committee 440 (2015), it is recommended to design beams with concrete crushing more than GFRP failure. The theoretical concrete compressive strain $\varepsilon_{c u}=0.003$ is taken into account as the ultimate compressive strain.

$$
\begin{gathered}
\rho_{f}=\frac{A_{f}}{b d} \\
\rho_{f b}=0.85 \beta_{1} \frac{f_{c}^{\prime}}{f_{f u}} \frac{E_{f} \varepsilon_{c u}}{E_{f} \varepsilon_{c u}+f_{f u}}
\end{gathered}
$$

The actual flexural compressive concrete stress distribution above the neural axis is nonlinear and in practice it is awkward to use this distribution. Therefore, the actual stress distribution is substituted by an equivalent rectangular concrete stress block by using cylindrical concrete compressive strength reduction factor $\alpha=0.85$ and the equivalent block depends on both concrete strength reduction factor $\alpha$, and $\beta_{1}$ which is the ratio between equivalent rectangular concrete compressive stress height $a$ to neutral axis depth $c$. The value of $\alpha=0.85$ and Equation (3) to determine $\beta_{1}$ were adopted from ACI Committee 318 (2019).

$$
\beta_{1}=\left\{\begin{array}{cc}
0.85 & \text { for } 17 \mathrm{MPa} \leq \dot{f_{c}} \leq 28 \mathrm{MPa} \\
0.85-0.05\left(\frac{f_{c}-28}{7}\right) & \text { for } 28 \mathrm{MPa}<\dot{f_{c}} \leq 55 \mathrm{MPa} \\
0.65 & \text { for } f_{c}>55 \mathrm{MPa}
\end{array}\right\}
$$

:muhammad.rashid@univsul.edu.iq; faris.rashied@koyauniversity.org; serwan.rafiq@univsul.edu.iq 
For compression control $\left(\rho_{f}>\rho_{f b}\right)$, theoretical nominal moment capacity is calculated by Equation (4) and the depth of rectangular concrete stress block is calculated using Equation (5). The actual tensile stress in GFRP rebars can be calculated as given in Equation (6), which is less than of its ultimate tensile strength. neutral axis depth $c$ from extreme compression fiber is found using Equation (7). The actual GFRP tensile strain is also calculated from Equation (8), which is corresponding to the theoretical ultimate concrete strain. The governing equations follow the same assumptions of the flexural theory used for conventional reinforced concrete beams. It can be noted that while $\rho_{f}>\rho_{f b}$, minimum area of GFRP rebars $A_{f, \min }$ is not required to be checked because the compression controlled failure governs the situation where the actual provided reinforcement area is greater than that of minimum limit from Equation (13).

$$
\begin{gathered}
M_{n}=A_{f} f_{f}\left(d-\frac{a}{2}\right) \\
a=\frac{A_{f} f_{f}}{0.85 f_{c}^{\prime} b} \\
f_{f}=\left(\sqrt{\left.\frac{\left(E_{f} \varepsilon_{c u}\right)^{2}}{4}+\frac{0.85 \beta_{1} f_{c}}{\rho_{f}} E_{f} \varepsilon_{c u}-0.5 E_{f} \varepsilon_{c u}\right) \leq f_{f u}}\right. \\
c=\frac{a}{\beta_{1}} \\
\varepsilon_{f}=\left(\frac{d-c}{c}\right) \varepsilon_{c u}
\end{gathered}
$$

For tension control $\left(\rho_{f}<\rho_{f b}\right)$, nominal moment capacity $M_{n}$ is calculated by Equation (9), where ultimate FRP tensile strength used as GFRP rupture occurs. Concrete stress block depth $a$ can be found from Equation (10). However, Equation (9)\&(10) are not recommended because of unknowns of the actual concrete strain concrete $\varepsilon_{c}$, and equivalent stress block parameters $\alpha$ and $\beta_{1}$. As a result, nominal moment strength for tension control beams are conservatively computed similar to that of balanced failure conditions, where $\varepsilon_{c u}=0.003$ and $\varepsilon_{f u}$ used as given in Equation (11) \& (12). Here, it is necessary to provide beams with FRP reinforcements not less than minimum GFRP reinforcement ratio, which can be found using Equation (13).

$$
\begin{gathered}
M_{n}=A_{f} f_{f u}\left(d-\frac{a}{2}\right) \\
a=\frac{A_{f} f_{f u}}{0.85 \dot{f}_{c}^{\prime} b} \\
M_{n}=A_{f} f_{f u}\left(d-\frac{\beta_{1} c_{b}}{2}\right) \\
c_{b}=\left(\frac{\varepsilon_{c u}}{\varepsilon_{c u}+\varepsilon_{f u}}\right) d
\end{gathered}
$$

:muhammad.rashid@univsul.edu.iq; faris.rashied@koyauniversity.org; serwan.rafiq@univsul.edu.iq 


$$
A_{f, \min }=\frac{0.41 \sqrt{f_{c}^{\prime}}}{f_{f u}} b_{w} d \geq \frac{2.3}{f_{f u}} b d
$$

From experimental point of view, the applied loads at failure $P_{n, \text { exp }}$ were recorded during flexural beam test. and the dimensions were also measured. The experimental flexural moment capacity at midspan $M_{n, \exp }$ was calculated using Equation (14) based on EulerBernoulli beam theory.

$$
M_{n, \exp }=\frac{P_{n, \exp }}{2} L_{s}
$$

\subsection{Cracking moment}

Cracking moment symbolized as $M_{c r}$ is defined as the moment, which causes the first crack of concrete beam. The calculation of the cracking moment depends on flexural strength of concrete $f_{r}$, gross moment of inertia $I_{g}$ and distance between centroid of the section and extreme tension fiber, $y_{t}=h / 2$. The flexural strength of concrete was computed in terms of concrete compressive strength according Equation (15), where lightweight concrete factor $\lambda=1$ for normal concrete. For rectangular section, the value of $y_{t}=h / 2$ and $I_{g}$ is calculated as given in Equation (16). As a result, Equation (17) was is used to find the predicted cracking moment.

$$
\begin{gathered}
f_{r}=0.62 \lambda \sqrt{f_{c}^{\prime}} \\
I_{g}=\frac{b h^{3}}{12} \\
M_{c r}=\frac{f_{r} I_{g}}{y_{t}}
\end{gathered}
$$

It is noted that experimental cracking loads were reported in the literature. For the calculation of the experimental cracking moment $M_{c r, \exp }$, while the first crack appeared on concrete beam the applied loads at first crack $P_{c r, \exp } \quad$ were documented. The experimental cracked moment at midspan was computed using Equation (18).

$$
M_{c r, \exp }=\frac{P_{c r, \exp }}{2} L_{s}
$$

\subsection{Ultimate Deflection}

The Euler-Bernoulli formula describes the relationship between the beam stiffness $E I$ and the internal moment $M$ as given in Equation
(19). It is simplified by taking double integration to calculate elastic deflection along the beam length while moment and stiffness are constant.

$$
\frac{d^{2} \Delta}{d x^{2}}=\frac{M}{E I}
$$

:muhammad.rashid@univsul.edu.iq; faris.rashied@koyauniversity.org; serwan.rafiq@univsul.edu.iq 
Due to concrete cracking while loading, the beam stiffness will vary because of decrease in moment of inertia $I$ up to beam failure. Therefore, the elastic deflection depends on the varying moment of inertia called effective moment of inertia $I_{e}$ and its corresponding moment $M_{a} \cdot I_{e}$ varies between gross moment of inertia of uncracked section $I_{g}$ and cracked moment of inertia section $I_{c r}$. has a moment of inertia equal to the gross moment of inertia, Ig. The stiffness also differs along the length of beam and the variation stiffness factor $\gamma$ was reported by Bischoff (2005) adopted by ACI 440 to include this variation. Equations (20) to (25) governs the calculation of $I_{e}$ according to elastic analysis of transferred beam composite section.

$$
\begin{gathered}
I_{c r}=\frac{b d^{3}}{3} k^{3}+n_{f} A_{f} d^{2}(1-k)^{2} \\
n_{f}=\frac{E_{f}}{E_{c}} \\
E_{c}=4700 \sqrt{f_{c}} \\
k=\sqrt{2 \rho_{f} n_{f}+\left(\rho_{f} n_{f}\right)^{2}}-\rho_{f} n_{f} \\
\gamma=1.72-0.72\left(\frac{M_{c r}}{M_{a}}\right) \\
I_{e}=\frac{I_{c r}}{1-\gamma\left(\frac{M_{c r}}{M_{a}}\right)^{2}\left[1-\frac{I_{c r}}{I_{g}}\right]} \leq I_{g}
\end{gathered}
$$

Theoretical midspan deflection $\Delta_{n}$ at max flexural capacity was calculated when $M_{a}=M_{n}$. For four point loading test, from
Equation (25) the ultimate loads were computed from moment capacities. Finally, $\Delta_{n}$ can be obtained by applying Equation (27).

$$
\begin{gathered}
P_{n}=\frac{2 M_{n}}{L_{s}} \\
\Delta_{n}=\frac{P_{n} L_{s}}{48 E_{c} I_{e}}\left(3 L_{n}{ }^{2}-4 L_{s}{ }^{2}\right)
\end{gathered}
$$

During flexural beam tests, the experimental deflections at midspan $\Delta_{n, \exp }$ were observed using the LVDT sensors while the concrete failure or FRP rupture occurred at its conforming $M_{n, \exp }$.

3.4. First Crack Deflection
First crack deflection occurs when the applied moment $M_{a}=M_{c r}$ and $I_{e}=I_{g}$. Beyond $M_{c r}$, concrete beam start cracking. The cracking load $P_{c r}$ and theoretical elastic cracking deflection $\Delta_{c r}$ can be calculated from Equation (28) \& (29), respectively.

:muhammad.rashid@univsul.edu.iq; faris.rashied@koyauniversity.org; serwan.rafiq@univsul.edu.iq 


$$
\begin{gathered}
P_{c r}=\frac{2 M_{c r}}{L_{s}} \\
\Delta_{c r}=\frac{P_{c r} L_{s}}{48 E_{c} I_{g}}\left(3 L_{n}{ }^{2}-4 L_{s}{ }^{2}\right)
\end{gathered}
$$

Regarding the investigational values, while the first crack occurs at $P_{c r, \text { exp }}$, experimental cracking deflection $\Delta_{c r, e x p}$ were recorded at midspan of the beam.

\subsection{Neural Axis Depth}

The theoretical neutral axis depth $c$ was found from Equation (7) for concrete crushing \& (12) for GFRP rupture, which was assumed $\varepsilon_{c u}=0.003$. The experimental depth of the neutral axis was calculated by Equation (30). Strain gauges were attached on the top of concrete beam and FRP rebars at midspan to measure $\varepsilon_{c u, e x p}$ and $\varepsilon_{f, \text { exp }}$, respectively. The effective beam depth $d$ calculated from top of the beam to centroid of GFRP reinforcements.

$$
c_{\exp }=\left(\frac{\varepsilon_{c u, \exp }}{\varepsilon_{c u, e x p}+\varepsilon_{f, \exp }}\right) d
$$

\section{RESULTS AND DISCUSSION}

Table 3 compares the results obtained from the literature and those calculated by ACI 440 recommendations for each beam. Due to a wide series of beam specimens and different materials properties, the data were fluctuated among those reported by the studies. However, the variations do not significantly affect the general trend. The common failure modes were concrete crushing as a consequence of $\rho_{f}>\rho_{f b}$. The beams of 2G12, , A25-1, A45-1, A70-1 were failed at GFRP rupture mode while their $\rho_{f} / \rho_{f b}$ ratio were $1.19,1.23,1.11$ and 1.46 , respectively. It is expected by ACI 440 that FRP rupture may occur at reinforcement ratio up to $1.4 \rho_{f b}$. Accordingly, it can be suggested to start designing GFRP reinforced concrete member

\begin{tabular}{|c|c|c|c|c|c|c|c|c|c|c|c|c|}
\hline \multirow{3}{*}{ Reference } & \multirow{3}{*}{ Beam ID } & \multicolumn{7}{|c|}{ Experimental } & \multicolumn{4}{|c|}{ ACl 440.1R.15 } \\
\hline & & $M_{c r, \exp }$ & $M_{n, \exp }$ & $\Delta_{n, \exp }$ & $\varepsilon_{f, \exp }$ & $\varepsilon_{c u, \exp }$ & $c_{\exp }$ & failure & $c$ & $M_{c r}$ & $M_{n}$ & $\Delta_{n}$ \\
\hline & & $k N . m$ & $k N . m$ & $m m$ & $\mu \varepsilon$ & $\mu \varepsilon$ & $\mathrm{mm}$ & mode & $\mathrm{mm}$ & $k N . m$ & $k N . m$ & $\mathrm{~mm}$ \\
\hline \multirow{4}{*}{$\begin{array}{l}\text { Kassem et al } \\
(2011)\end{array}$} & G1-6 & 10.92 & 77.47 & 51.8 & 12436 & 3269 & 48 & C.C & 56 & 11.62 & 60.44 & 37.6 \\
\hline & G1-8 & 11.37 & 86.76 & 48 & 11240 & 3210 & 52 & C.C & 63 & 11.62 & 67.41 & 33.2 \\
\hline & G2-6 & 11.15 & 71 & 50.8 & 14400 & 3100 & 41 & C.C & 51 & 11.62 & 55.73 & 41.3 \\
\hline & $\mathrm{G} 2-8$ & 11.34 & 84.54 & 50.3 & 11470 & 3150 & 50 & C.C & 58 & 11.62 & 62.37 & 36.5 \\
\hline \multirow{4}{*}{$\begin{array}{l}\text { El-Nemr et al } \\
(2018)\end{array}$} & 3\#13G1 & 13.46 & 81.34 & 64.2 & 13726 & 1561 & 36 & C.C & 61 & 19.14 & 92.23 & 62.0 \\
\hline & 5\#13G1 & 15.26 & 130.6 & 76.8 & 15095 & 1933 & 39 & C.C & 72 & 20.64 & 115.87 & 52.9 \\
\hline & 2\#13G2 & 13.75 & 82.78 & 71.7 & 16359 & 2541 & 46 & C.C & 57 & 19.14 & 84.99 & 64.9 \\
\hline & 3\#15G1 & 12.22 & 101.3 & 51.6 & 13345 & 2341 & 51 & C.C & 68 & 20.64 & 109.83 & 55.8 \\
\hline
\end{tabular}
with $\rho_{f}=1.5 \rho_{f b}$ to avoid tension failure.

Table (3): Experimental values against ACI 440.1R.15 design

:muhammad.rashid@univsul.edu.iq; faris.rashied@koyauniversity.org; serwan.rafiq@univsul.edu.iq 
Journal of University of Duhok, Vol.23, No.2 (Pure and Eng. Sciences), Pp 630-647, 2020 (Special Issue) $3^{\text {rd }}$ international conference on recent innovations in engineering (ICRIE) Duhok, September 9-10-2020

\begin{tabular}{|c|c|c|c|c|c|c|c|c|c|c|c|c|}
\hline & 4\#15G1 & 15.61 & 138.2 & 65.1 & 13489 & 1816 & 41 & C.C & 77 & 20.64 & 123.29 & 49.2 \\
\hline & 2\#15G2 & 11.22 & 95.93 & 62.9 & 14136 & 1454 & 32 & C.C & 73 & 17.81 & 94.74 & 50.8 \\
\hline & 2\#15G3 & 10.92 & 91.31 & 70 & 10277 & 2129 & 59 & C.C & 65 & 19.23 & 95.62 & 57.7 \\
\hline & 6\#15G1 & 11.98 & 118.3 & 42.6 & 7693 & 1976 & 65 & C.C & 92 & 19.14 & 120.21 & 39.8 \\
\hline & $5 \# 15 G 2$ & 12.2 & 129.3 & 46.9 & 7550 & 2959 & 93 & C.C & 106 & 17.81 & 125.57 & 34.1 \\
\hline & $5 \# 15 G 3$ & 12.61 & 110.6 & 40.7 & 6430 & 1839 & 74 & C.C & 95 & 19.22 & 128.70 & 38.9 \\
\hline & 2\#20G1 & 15.36 & 107.4 & 68.2 & 13372 & 2090 & 46 & C.C & 69 & 20.64 & 110.47 & 54.9 \\
\hline & 3\#20G1 & 16.32 & 140.4 & 61.5 & 6794 & 3087 & 106 & C.C & 81 & 21.46 & 134.02 & 47.2 \\
\hline & 2\#22G1 & 12.88 & 132.3 & 53.5 & 13651 & 2646 & 55 & C.C & 74 & 20.64 & 117.50 & 51.2 \\
\hline & 3\#20G2 & 12.29 & 171.4 & 59 & 11823 & 2648 & 62 & C.C & 81 & 22.94 & 146.55 & 47.0 \\
\hline & 2\#25G1 & 11.32 & 161.7 & 60 & 10028 & 2529 & 68 & C.C & 83 & 22.94 & 147.91 & 46.1 \\
\hline & 2\#25G2 & 16.77 & 167.2 & 53.3 & 7573 & 2045 & 72 & C.C & 91 & 22.94 & 160.93 & 41.8 \\
\hline & 2\#25G3 & 13.2 & 115.9 & 40.7 & 6429 & 1627 & 68 & C.C & 96 & 19.22 & 133.30 & 38.6 \\
\hline Wang \& Belarbi & P4G-1 & $N G$ & 46 & 26.2 & 11470 & 3000 & 38 & C.C & 47 & 6.68 & 40.36 & 18.8 \\
\hline (2011) & P8G-1 & $N G$ & 50.9 & 24.4 & 8250 & 2800 & 45 & C.C & 54 & 6.68 & 44.19 & 16.0 \\
\hline \multirow{6}{*}{$\begin{array}{l}\text { Toutanji \& Deng } \\
\text { (2003) }\end{array}$} & GB1-1 & 11.7 & 60 & 70 & $N G$ & $N G$ & NG & C.C & 40 & 9.90 & 43.39 & 47.0 \\
\hline & GB1-2 & 12.3 & 59 & 73 & $N G$ & $N G$ & NG & C.C & 40 & 9.90 & 43.39 & 47.0 \\
\hline & GB2-1 & 13.4 & 65 & 60 & $N G$ & $N G$ & $N G$ & C.C & 48 & 9.90 & 51.51 & 39.4 \\
\hline & GB2-2 & 12.8 & 64.3 & 59 & $N G$ & $N G$ & $N G$ & C.C & 48 & 9.90 & 51.51 & 39.4 \\
\hline & GB3-1 & 11.8 & 71 & 61 & $N G$ & $N G$ & $N G$ & C.C & 53 & 9.90 & 53.52 & 35.2 \\
\hline & GB3-2 & 11.6 & 70.5 & 62 & $N G$ & $N G$ & $\mathrm{NG}$ & C.C & 53 & 9.90 & 53.52 & 35.2 \\
\hline \multirow{3}{*}{$\begin{array}{l}\text { El Refai et al } \\
(2015)\end{array}$} & $2 \mathrm{G} 12$ & $N G$ & 49.03 & 105.2 & $N G$ & $N G$ & NG & G.R & 34 & 13.53 & 47.58 & 105.4 \\
\hline & $3 G 12$ & $N G$ & 53.78 & 108.2 & $N G$ & $N G$ & $N G$ & C.C & 42 & 13.53 & 56.62 & 89.9 \\
\hline & $3 G 16$ & $N G$ & 69.55 & 81 & $N G$ & $N G$ & $N G$ & C.C & 53 & 13.53 & 70.76 & 70.7 \\
\hline \multirow{6}{*}{$\begin{array}{l}\text { Barris et al } \\
(2009)\end{array}$} & C-212-D1 & $N G$ & 38.22 & 52.2 & $N G$ & $N G$ & $N G$ & C.C & 35 & 4.04 & 24.24 & 28.0 \\
\hline & C-216-D1 & $N G$ & 45.06 & 40.5 & $N G$ & $N G$ & NG & C.C & 46 & 3.92 & 29.17 & 21.2 \\
\hline & C-316-D1 & $N G$ & 49.38 & 32.5 & $N G$ & $N G$ & NG & C.C & 54 & 3.88 & 33.43 & 18.0 \\
\hline & C-212-D2 & $N G$ & 27.69 & 47.8 & $N G$ & $N G$ & $N G$ & C.C & 34 & 3.76 & 18.11 & 27.2 \\
\hline & C-216-D2 & $N G$ & 42.15 & 45.4 & $N G$ & $N G$ & $N G$ & C.C & 38 & 4.69 & 26.79 & 25.1 \\
\hline & C-316-D2 & $N G$ & 43.2 & 38.6 & $N G$ & $N G$ & $\mathrm{NG}$ & C.C & 46 & 4.63 & 30.60 & 21.1 \\
\hline \multirow{6}{*}{$\begin{array}{l}\text { Goldston et al } \\
\text { (2016) }\end{array}$} & $40 \# 2-0.5-S$ & 1.00 & 4.6 & 52.2 & G.F & 1400 & NG & B.F & 17 & 1.47 & 5.48 & 62.3 \\
\hline & 40\#3-1.0-S & 1.67 & 13.1 & 60.4 & 12000 & 2900 & 25 & C.C & 30 & 1.47 & 8.87 & 37.6 \\
\hline & $40 \# 4-2.0-S$ & 1.93 & 16.6 & 59.9 & 9800 & 3300 & 31 & C.C & 36 & 1.47 & 10.28 & 31.1 \\
\hline & $80 \# 2-0.5-S$ & 1.20 & 5.17 & 54.5 & G.F & 1000 & $N G$ & G.R & 10 & 2.08 & 5.77 & 58.5 \\
\hline & $80 \# 3-1.0-S$ & 1.97 & 14.2 & 56.3 & G.F & 2200 & NG & C.C & 24 & 2.08 & 12.32 & 49.9 \\
\hline & $80 \# 4-2.0-5$ & 1.90 & 16.5 & 47.3 & 9300 & 2700 & 28 & C.C & 28 & 2.08 & 14.48 & 41.5 \\
\hline \multirow{4}{*}{$\begin{array}{l}\text { Adam et al } \\
(2015)\end{array}$} & A25-1 & 5.61 & 25.25 & 84 & 13000 & $N G$ & $\mathrm{NC}$ & G.R & 34 & 4.94 & 13.58 & 38.6 \\
\hline & A25-2 & 5.94 & 22.39 & 55 & 14000 & $N G$ & $\mathrm{NC}$ & SG.R & 42 & 4.94 & 16.69 & 32.6 \\
\hline & A25-3 & 5.99 & 41.36 & 90 & 17000 & $N G$ & $\mathrm{NC}$ & C.C & 54 & 4.94 & 20.72 & 26.3 \\
\hline & A45-1 & 8.69 & 30.69 & 80 & 15000 & NG & $\mathrm{NC}$ & G.R & 32 & 6.92 & 23.38 & 44.5 \\
\hline
\end{tabular}

muhammad.rashid@univsul.edu.iq; faris.rashied@koyauniversity.org; serwan.rafiq@univsul.edu.iq

${ }^{1}$ Corresponding author: College of Engineering, University of Sulaimani, Kurdistan Region, Iraq. 
Journal of University of Duhok, Vol.23, No.2 (Pure and Eng. Sciences), Pp 630-647, 2020 (Special Issue)

$3^{\text {rd }}$ international conference on recent innovations in engineering (ICRIE) Duhok, September 9-10-2020

\begin{tabular}{lllllllllllll}
\hline A45-2 & 8.47 & 45.05 & 85 & 15000 & NG & NC & C.C & 41 & 6.92 & 29.41 & 36.2 \\
\hline & A45-3 & 9.68 & 60.39 & 78 & 15000 & NG & NC & C.C & 52 & 6.92 & 36.04 & 29.4 \\
\hline & A70-1 & 8.97 & 46.53 & 88 & 13000 & NG & NC & G.R & 37 & 8.61 & 34.49 & 41.1 \\
\hline & A70-2 & 8.53 & 72.99 & 95 & 13000 & NG & NC & C.C & 46 & 8.61 & 42.57 & 33.7 \\
\hline
\end{tabular}

Note, C.C is top fiber concrete crushing, G.R is GFRP rupture, B.F is balanced failure of both top and GFRP at the same time, G.F. is strain gauge failure, NG is not available in the reference, NC cannot be calculated due to lack of concrete strain, SG.R is suddenly GFRP failure before reaching its tested tensile strength.

Figure 2 shows the ratio of experimental to ACI 440 predicted nominal moment capacities $M_{n, \exp } / M_{n}$ at failure. the majority of ratios evidently presented that ACI 440.1R-15 underestimated the calculated flexural moment compared to the experimental load carrying capacity. The moment ratios varied between 0.84 and 2 with the mean value of 1.25. Among 53 beams, $77 \%$ of their moment ratios were greater than 1 while the remaining moment ratios (23\%) ranged between 0.84 and 1. All the moment ratios obtained from (Toutanji and Deng 2003, Barris et al 2009, Kassem et al 2011, Wing \& Belari 2011, Adem et al 2015) showed that GFRP reinforced concrete beams can carry loads more than those predicted by ACI 440. $\rho_{f}$ mostly differs from $0.34 \%$ to $2.32 \%$. Looking at the moment ratios calculated from (Goldston et al 2016), the ratios increased with increasing GFRP reinforcement ratio. For instance, it was 0.84 at $\rho_{f}=0.5 \%$ and considerably reached 1.62 at $\rho_{f}=2 \%$. However, there is no clear trend between $\rho_{f}$ and $M_{n, \exp } / M_{n}$ considering different works due to fluctuation of the moment ratios along $\rho_{f}$. Because the failure of the beams was concrete crushing the increased reinforcement ratio did not have significant effect on moment capacity of the beams.

Regarding midspan ultimate deflections at failure, Figure 3 shows the deflection ratios $\Delta_{n, \text { exp }} / \Delta_{n}$ between the experimental deflection to theoretical deflection obtained from ACI 440. It was observed that ultimate deflections calculated by ACI 440 underestimated the deflection compared to the experimental observations. The deflection ratios ranges between 0.84 and 3.32 with an average of 1.55. It can be noted that 7 out of 9 moment ratios obtained from (Adam et al 2015) reached above 2 , whereas all remaining moment ratios obtained were under 2. A major number of tested beams (94\%) revealed that the theoretical deflections undervalued less than those measured in the laboratory. Figure 3 also gives the ratios of effective to gross moment of inertia $I_{e} / I_{g}$ corresponding to their ultimate moment ratios, frequently ranged between 0.04 and 0.22 . due to the geometrical variety of specimens, the dispersions of $\Delta_{n, \text { exp }} / \Delta_{n}$ occurs and it is weak to establish equation between both ratios.

:muhammad.rashid@univsul.edu.iq; faris.rashied@koyauniversity.org; serwan.rafiq@univsul.edu.iq

$642{ }^{1}$ Corresponding author: College of Engineering, University of Sulaimani, Kurdistan Region, Iraq. 


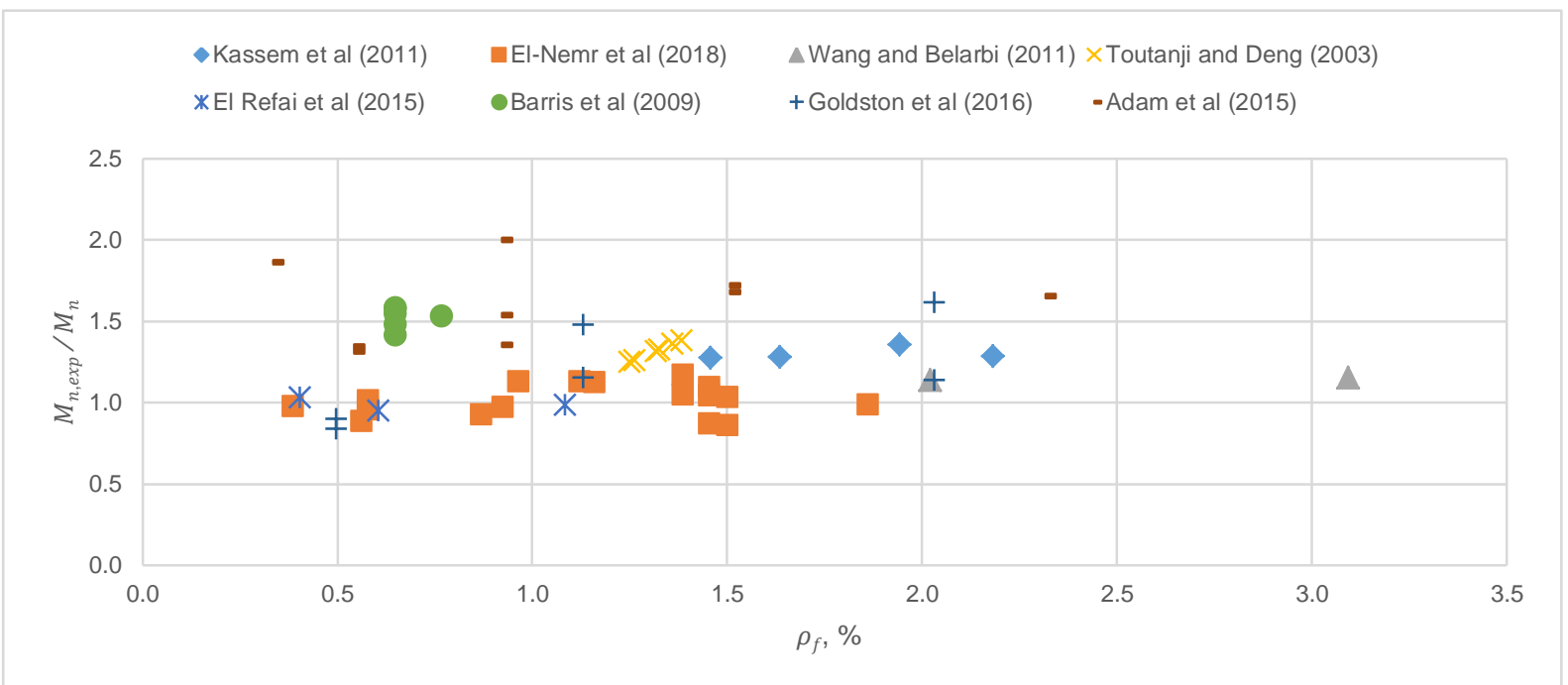

Fig. (2): Experimental to predicted nominal moment ratio versus GFRP reinforcement ratio

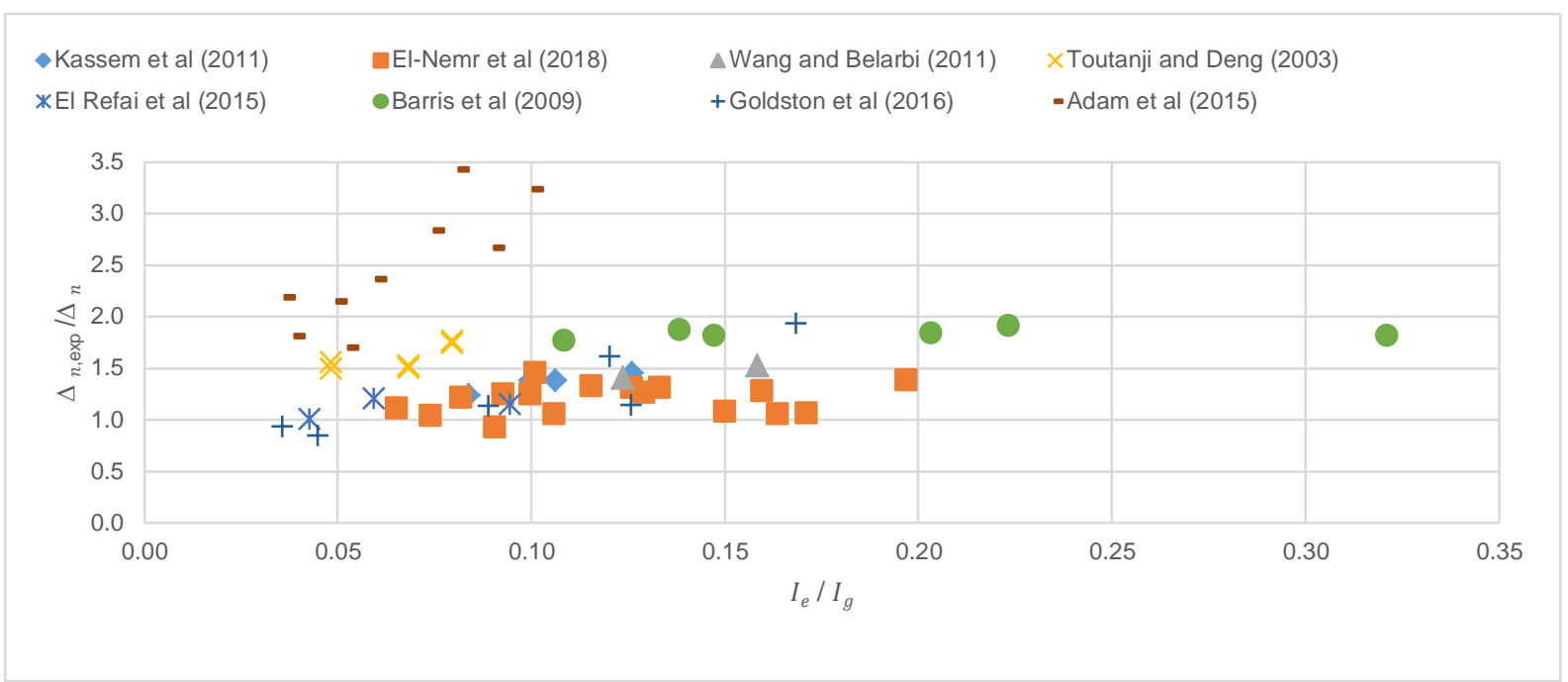

Fig. (3): Experimental to predicted ultimate deflection ratio versus gross to effective sectional moment ratio

Figure 4 shows the ratios of experimental cracking moment at $P_{c r, e x p}$ to theoretical cracking moment calculated by Equation (17) at $P_{c r}$ with respected to theoretical flexural strength of concrete estimated by Equation (15). The concrete flexural strength is the controlling parameter for calculating cracking moment. All experimental cracking moments obtained by (Kassem et al 2011, EL-Nemr et al (2018) were less than those predicted by ACI 440, whereas they were conservative according to Toutanji and Deng (2003). The cracking moment data were available for 42 beams. It can be seen that $M_{c r, \text { exp }} / M_{c r}$ ratios vary between 0.49 and 1.4 with an average of 0.92. Regarding to the cracking deflection ratio $\Delta_{c r, \exp } / \Delta_{c r}$, Only two of the works stated cracking deflections for their tested beams. El-Nemr et al (2018) reported that first crack occurs at the deflections of less than 3 $\mathrm{mm}$ without reporting the data. Kassem et al (2011) presents that the cracking deflections for the beams G1-6, G1-8, G2-6, and G2-8 were (2.9, 2.8, 3.2 and 3) $\mathrm{mm}$, respectively while theoretical cracking deflection calculated from Equation (29) is equal to $0.72 \mathrm{~mm}$. The experimental cracking deflection are about four times greater than those calculated by ACI 440. There are two main reasons for the difference between both faris.rashied@koyauniversity.org; serwan.rafiq@univsul.edu.iq

${ }^{1}$ Corresponding author: College of Engineering, University of Sulaimani, Kurdistan Region, Iraq. 
theoretical and experimental results. Firstly, the flexural tensile of concrete $f_{r}=0.62 \lambda \sqrt{f_{c}^{\prime}}$ could be various from the actual flexural strength of the concrete. Secondly, the experimental cracking deflection cannot have observed at pre-cracking loads and the beam already cracked. In this critical situation, $I_{g}$ that is used in the calculation of theoretical deflection is more than that moment of inertia of the beam.

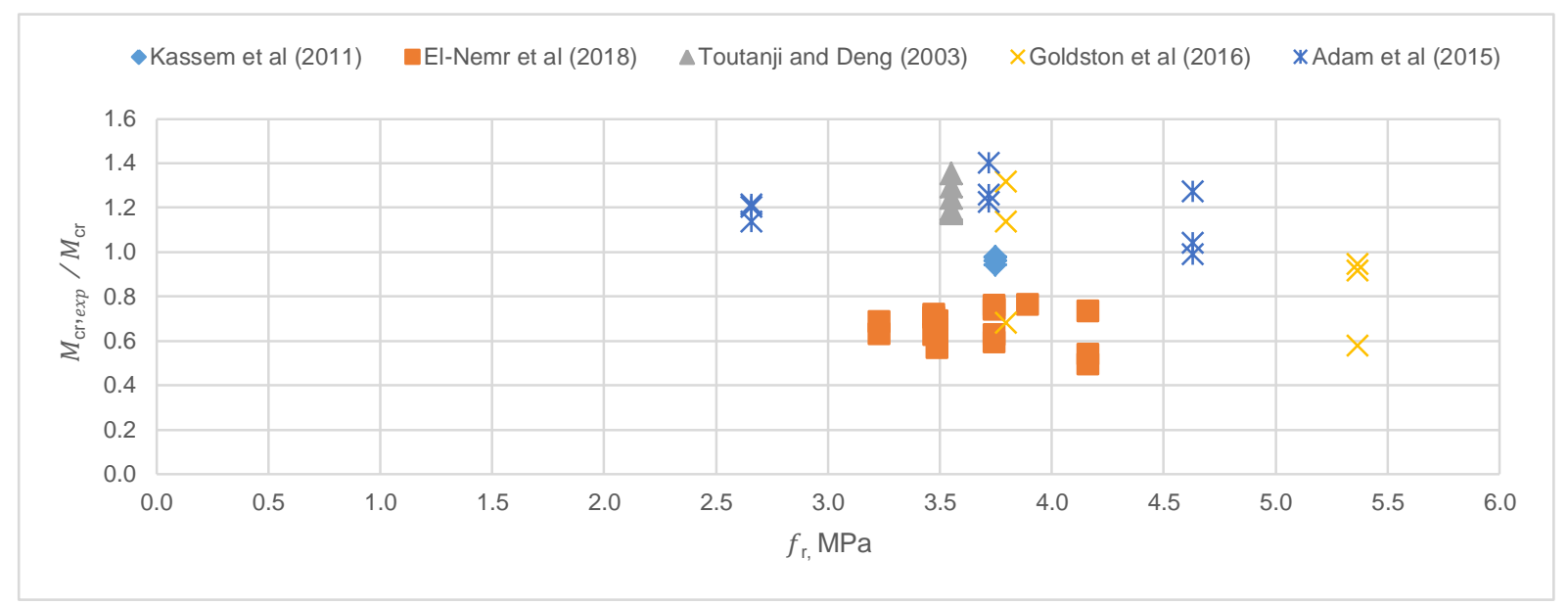

Fig. (4): Experimental to predicted cracking moment ratio versus concrete flexural strength

Figure 5 presents the ratios of the experimental neutral axis depth to theoretical neural axis depth of the beam section at failure. The experimental neutral axis depths were calculated by Equation (30) on the basis of strains measured by the top and bottom strain gauges. Due to lack of data and strain gauge ruptures, among 53 beams, experimental neutral axis can be found for 26 beams. The results showed that experimental neural axis depth were less than the theoretical values except 3\#20G1. Without considering outliers, the experimental to predicted neutral axis depth ratios ranges between 0.527 to 0.989 with an average with 0.786. The reason for these decreased neural depth ratios belongs to concrete crushing failure, and adopted equivalent rectangular stress block parameters $\left(\alpha\right.$ and $\left.\beta_{1}\right)$ from ACI 318. It can be noted that $\beta_{1}$ is limited to 0.65 beyond cylindrical compressive strength of $55 \mathrm{MPa}$. The results revealed that equivalent rectangular stress block parameters need to be adjusted for GFRP reinforced concrete member.

:muhammad.rashid@univsul.edu.iq; faris.rashied@koyauniversity.org; serwan.rafiq@univsul.edu.iq 


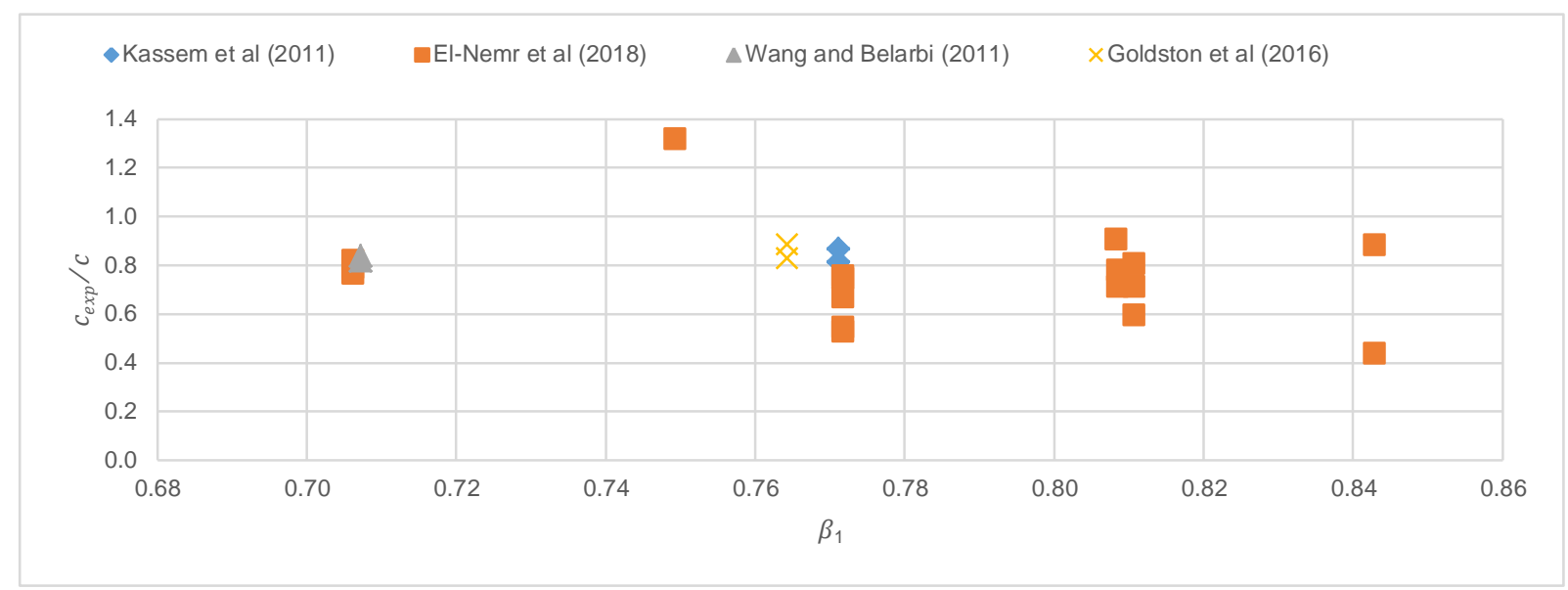

Fig. (5): Experimental to predicted neutral axis depth ratio versus an equivalent stress block parameter

The statistical data analysis provided by box and whisker method showed to the represented values such mean, median, first and second quadrantes, outliers for the ratios of the experimental to theoretical ultimate moment, cracking moment, ultimate deflection and neutral axis depth as shown in Figure 6. Except the cracking moment ratios, the other ratios had outliers, which taken out of the calculated median. For instance, the outliers for ultimate deflection ratios were $2.82,3.22$ and 3.42 .
According to the analysis and based on the median of the values, the modification factors are estimated to be used during design. The modification factor for the experimental to ACI 440.1R-15 ultimate moment, cracking moment, ultimate deflection and neutral axis depth can be $1.25,0.94,1.4$ and 0.806 , respectively in addition, these areas required standardizing the manufacturing process of GFRP bar internationally to avoid the market discrepancies.

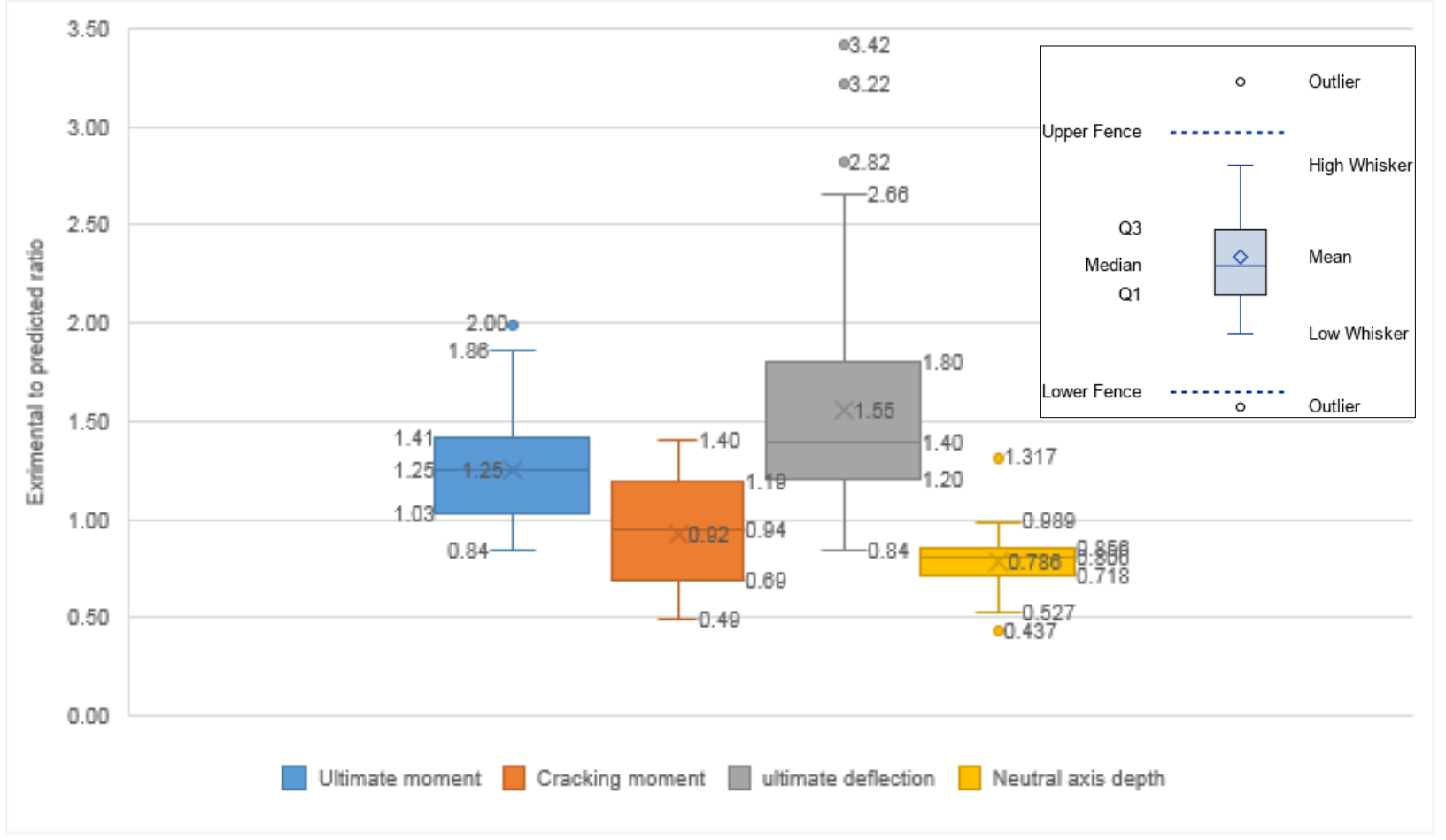

Fig. (6): Statistical data analysis according to box and whisker method muhammad.rashid@univsul.edu.iq; faris.rashied@koyauniversity.org; serwan.rafiq@univsul.edu.iq

${ }^{1}$ Corresponding author: College of Engineering, University of Sulaimani, Kurdistan Region, Iraq. 


\section{CONCLUSION}

Investigational test results of 53 GFRP reinforced concrete beams that tested under four-point loading test to failure were gathered from the literature. The concrete beams covering a variety of dimensional properties were made of GFRP rebar for longitudinal flexural reinforcement and steel rebar for traverse reinforcement. The beam data selected from different studies, and GFRP rebars that used have different modulus of elasticity, tensile-strength, and GFRP reinforcement ratio and configuration. The investigational results were compared with those predicted by ACI 440.1R-15 in terms of the cracking and flexural moments, cracking and ultimate deflections, and neural axis depth. On the basis of the experimental and theoretical results, the following conclusions can be drawn:

- The database of 53 GFRP reinforced concrete beam with dimensional and materials properties have been collected, which tested by others with pure bending flexural test and failed in flexure.

- Due to lack of a comprehensive numerical detail in the literature, an understanding approach has been presented to compute the experimental deflection and flexural capacity compared with the theoretical equations given in ACI 440.1R-15, which has provided new researchers with an adequate starting in the field.

- Nominal moment capacity has been negligibly affected by increasing GFRP reinforcement ratios because GFRP reinforcement ratios were greater than GFRP balanced ratio while the concrete crushed controlled failure mode. The investigational results showed underestimate of ultimate moment achieved by ACI 440. The modification factor (1.25) has been predictable.

- Three beams have failed in GFRP rupture while their GFRP reinforcement ratios were greater than the balanced reinforcement ratios up to $1.46 \rho_{f b}$. To ensure compression failure, it has been given to use more than $1.5 \rho_{f b}$.

- GFRP reinforced concrete beams experienced the experimental ultimate deflections more than those calculated by ACI 440 . The variances have reached up to 3.5 times, and the modification factor was proposed to be 1.4.

- The majority of the experimental cracking moments was commonly less than the predicted results. However, the cracking moment ratios are close and the justification value of 0.94 was proposed. In addition, for the available data it has been concluded that the predicted cracking deflections were underestimated.

- The experimental results have given the neural axis depth less than those obtained from theoretical calculation. The value of 0.806 has been assessed to justify the predicted neutral axis depth. it has been concluded that the main reason behind these gaps related to the equivalent rectangular stress block parameters

\section{REFERENCES}

ACI Committee 318 (2019). Building code requirements for structural concrete and commentary (ACI 318-19). Farmington Hills, MI: American Concrete Institute.

ACI Committee 440. (2015). Guide for the Design and Construction of structural concrete reinforced with Fiber Reinforced Polymer (FRP) bars (ACI 440.1 R-15). Farmington Hills, MI: American Concrete Institute.

Adam, M. A., Said, M., Mahmoud, A. A., \& Shanour, A. S. (2015). Analytical and experimental flexural behavior of concrete beams reinforced with glass fiber reinforced polymers bars. Construction and Building Materials, 84, 354-366.

Alsayed, S. H., Al-Salloum, Y. A., \& Almusallam, T. H. (2000). Performance of glass fiber reinforced plastic bars as a reinforcing material for concrete structures. Composites Part B: Engineering, 31(6-7), 555-567.

:muhammad.rashid@univsul.edu.iq; faris.rashied@koyauniversity.org; serwan.rafiq@univsul.edu.iq

${ }^{1}$ Corresponding author: College of Engineering, University of Sulaimani, Kurdistan Region, Iraq. 
Ashour, A. F. (2006). Flexural and shear capacities of concrete beams reinforced with GFRP bars. Construction and Building Materials, 20(10), 1005-1015.

Bank, L. C. (2006). Composites for construction: structural design with FRP materials. John Wiley \& Sons.

Barris, C., Torres, L., Turon, A., Baena, M., \& Catalan, A. (2009). An experimental study of the flexural behaviour of GFRP RC beams and comparison with prediction models. Composite Structures, 91(3), 286-295.

Benmokrane, B., Chaallal, O., \& Masmoudi, R. (1995). Glass fibre reinforced plastic (GFRP) rebars for concrete structures. Construction and Building Materials, 9(6), 353-364.

Bischoff, P. H. (2005). Reevaluation of deflection prediction for concrete beams reinforced with steel and fiber reinforced polymer bars. Journal of structural engineering, 131(5), 752-767.

Burgoyne, C. J., Byars, E., Guadagnini, M., Manfredi, G., Neocleous, K., Pilakoutas, K., ... \& Al Sunna, R. (2007). FRP reinforcement in RC structures.

El Refai, A., Abed, F., \& Al-Rahmani, A. (2015). Structural performance and serviceability of concrete beams reinforced with hybrid (GFRP and steel) bars. Construction and Building Materials, 96, 518-529.

El-Nemr, A., Ahmed, E. A., El-Safty, A., \& Benmokrane, B. (2018). Evaluation of the flexural strength and serviceability of concrete beams reinforced with different types of GFRP bars. Engineering Structures, 173, 606-619.

Emparanza, A. R., Kampmann, R., De Caso, Y., \&
Basalo, F. (2018). State-of-the-Practice of Global Manufacturing of FRP Rebar and Specifications. Special Publication, 327, 45-1. Goldston, M., Remennikov, A., \& Sheikh, M. N. (2016). Experimental investigation of the behaviour of concrete beams reinforced with GFRP bars under static and impact loading. Engineering Structures, 113, 220-232. Kalpana, V. G., \& Subramanian, K. (2011). Behavior of concrete beams reinforced with GFRP BARS. Journal of reinforced plastics and composites, 30(23), 1915-1922.

Kassem, C., Farghaly, A. S., \& Benmokrane, B. (2011). Evaluation of flexural behavior and serviceability performance of concrete beams reinforced with FRP bars. Journal of Composites for Construction, 15(5), 682-695.

Tighiouart, B., Benmokrane, B., \& Gao, D. (1998). Investigation of bond in concrete member with fibre reinforced polymer (FRP) bars. Construction and building materials, 12(8), 453-462.

Toutanji, H. A., \& Saafi, M. (2000). Flexural behavior of concrete beams reinforced with glass fiber-reinforced polymer (GFRP) bars. Structural Journal, 97(5), 712-719.

Toutanji, H., \& Deng, Y. (2003). Deflection and crack-width prediction of concrete beams reinforced with glass FRP rods. Construction and Building Materials, 17(1), 69-74.

Wang, H., \& Belarbi, A. (2011). Ductility characteristics of fiber-reinforced-concrete beams reinforced with FRP rebars. Construction and Building Materials, 25(5), 2391-2401.

:muhammad.rashid@univsul.edu.iq; faris.rashied@koyauniversity.org; serwan.rafiq@univsul.edu.iq 